\title{
Wave-induced bedload transport - a study of the southern Baltic coastal zone
}

\author{
Aleksandra Dudkowska* \& Gabriela Gic-Grusza \\ University of Gdańsk, Institute of Oceanography, Piłsudskiego 46, 81-378 Gdynia, Poland \\ *corresponding author, e-mail: a.dudkowska@ug.edu.pl
}

\begin{abstract}
The wave-induced bedload transport and spatial distribution of its magnitude in the southern Baltic coastal zone of Poland are estimated. The vicinity of Lubiatowo was selected as a representative part of the Polish coast. It was assumed that transport is a function of shear stress; alternative approaches, based on force balances and discharge relationships, were not considered in the present study. Four models were studied and compared over a wide range of bottom shear stress and wind-wave conditions. The set of models comprises classic theories that assume a simplified influence of turbulence on sediment transport (e.g., advocated by authors such as Du Boys, Meyer-Peter and Müller, Ribberink, Engelund and Hansen). It is shown that these models allow to estimate transport comparable to measured values under similar environmental conditions. A united general model for bedload transport is proposed, and a set of maps of wave bedload transport for various wind conditions in the study area is presented.
\end{abstract}

Keywords: sediment transport models, non-cohesive sediments, bottom shear stress, northern Europe

\section{Introduction}

Although knowledge of sediment transport processes in the coastal zone is crucial for integrated coastal zone management and many engineering applications (i.e., coastal and marine spatial planning, construction of offshore wind farms, harbour constructions, jetties, sea outfall pipes and other marine constructions) there is a lack of data on details of such processes in the Polish Marine Areas (PMA). In particular accurate estimates of transport volume and direction are needed in order to define the relationships between human activities and seabed response. A first step, which will help to fill gaps in our knowledge, is to estimate waveinduced bedload transport (which is the prevailing mode of transport in the study area; details in section 2.4 below) and its spatial distribution based on classic approaches and mean wave properties. Further research will be related to the effect of wind currents, wave-generated currents, wave asymmetry as well as estimates of suspended sediment transport in the area of interest.

Sediment transport is a complex phenomenon which is influenced by dynamic processes such as wave motion, wave-induced currents, turbulence, sediment interactions, etc. Although numerous attempts have been made to develop high-quality sediment transport models, there are still a lot of gaps in our understanding and description of this process. Most of the equations used to calculate the rate of sediment transport rate were developed by using relatively simple physical models with coefficients resulting from a limited amount of data. In most cases the models are empirical because analytical solutions are unavailable; for further information reference is made to e.g. Bakhtyar et al. (2009).

The accuracy of the models discussed can be improved through assimilation with measurements. However, this is difficult because of an insufficient 
number and quality of sediment transport data. There are only few papers about in-situ measurements of sediment transport in the Polish coastal areas; one of these is that by Pruszak \& Zeidler (1995).

In a number of papers the pattern of bedload fluxes along the southern Baltic coast has been discussed. For example, Cieślak (1985) presented the direction of fluxes along the Polish coast. Data for the eastern coast of the Baltic Sea, from the Sambian Peninsula to Pärnu Bay, were represented by Viška \& Soomere (2013). Such research estimates the total volume of sediments that are transported alongshore. However, in order to determine spatial distribution of instantaneous transport for local, complex seabed configuration, the most adequate method is the use of one-grid-point models. Selecting the appropriate model seems to be essential at this stage of work. Since most bedload transport formulas yield similar results over a wide range of wave conditions, we compared only some wellknown empirical formulas, including those based on the probabilistic theory introduced in sediment modelling by Einstein (1950). A comparison of more complex sediment transport models was presented for example by Davies et al. (2002).

In the present paper we made an attempt to analyse wave-induced sediment transport magnitude (which is assumed to be only bedload transport, for details see section 2.2.4) in the coastal zone of Polish Marine Areas (PMAs). Although there are 18 sediment classes described for the PMA, from the finest muds to the coarsest cobbles and boulders, the coastal zone seabed is usually covered by sands, most of which are fine and medium grained (grain size in the range of $0.063-0.63 \mathrm{~mm}$ according to PN-EN ISO 14688:2006) (Gic-Grusza et al., 2009). As a first approximation, we assumed the sediment is homogeneous, with grain size equal to $0.22 \mathrm{~mm}$ (for details see section 2.4) and that there are no cohesive effects.

The bedload transport, understood as the movement of bedload particles by rolling, sliding and hopping (e.g., Soulsby, 1998), can be characterised as the product of the thickness of the sediment layer (which depends on shear stress at the bottom) and the speed of the layer (which depends on the square root of shear stress, i.e., friction velocity). Therefore, according to the earliest theories (e.g., Du Boys, 1879), transport is a function of the shear stress raised to the power of 1.5. Modifications of this figure led to the development of a group of models based on bottom shear stress. Alternative approaches, which are based on force balances and discharge relationships, were not considered in the present study.
The transport can be characterised by using a non-dimensional quantity $Q^{*}$ which is called the Einstein parameter (see Einstein, 1950). Dimensional quantities, such as volumetric $Q_{v}$ and mass $Q_{m}$ transport, are obtained for a specific grain size $D$, sediment density $\rho_{s}$ and fluid density $\rho$. The volumetric transport is the volume of sediments transported during $1 \mathrm{~s}$ per unit channel width, whereas mass transport is the mass transferred during $1 \mathrm{~s}$ :

$$
\begin{gathered}
Q_{v}=Q^{*}\left(\Delta g D^{3}\right)^{1 / 2}\left[\mathrm{~m}^{2} \cdot \mathrm{s}^{-1}\right] \\
Q_{m}=Q_{v} \rho_{s}=\rho_{s} Q^{*}\left(\Delta g D^{3}\right)^{1 / 2}\left[\mathrm{~kg} \cdot \mathrm{m}^{-1} \mathrm{~s}^{-1}\right]
\end{gathered}
$$

The present paper is organised as follows. Section 2 describes methods used, in particular models which are used to calculate bottom shear stress, friction factor, bedload transport as well as area of interest. Wave models used and weather conditions chosen for the tests are also described. Section 3 includes results of estimates of single-grid-point bedload transport based on all tested formulas, cross-shore distribution of wave-induced bedload transport in the area considered and spatial distribution of estimated values of bedload transport. Moreover, a unified formula for transport is introduced here and information on the possibility of the adjustment of the model coefficients is given. The final section is devoted to a discussion of the results.

\section{Material and methods}

\subsection{Bottom shear stress}

The bottom shear stress $\tau$ is the basic quantity used to determine sediment transport. It is a frictional force exerted on a unit area of seabed by current flowing over it. This quasi-stationary approach assumes that instantaneous stress can be determined on the basis of flow velocity outside the boundary layer $(U)$ :

$$
\tau=\rho f_{w} U|U| / 2
$$

which is one of the definitions of stress, valid for moderate speed flows and widely used in coastal zone applications. Sediment movement begins after a critical value of shear stress is exceeded. In order to estimate critical bed shear stress for initiation of sediment particle motion, empirical formulas were proposed (Dey, 2011), e.g.:

- Kramer (1935): 


$$
\tau_{c r}=29(\Delta \rho g D)^{1 / 2} M^{-1 / 2}\left[\mathrm{~g} \cdot \mathrm{m}^{-2}\right]
$$

for $0.24 \mathrm{~mm} \leq D \leq 6.52 \mathrm{~mm}, 0.27 \leq M \leq 1$,

- USWES (1936):

$$
\tau_{c r}=0.285(\Delta D)^{1 / 2} M^{-1 / 2}\left[\mathrm{~kg} \cdot \mathrm{m}^{-1} \mathrm{~s}^{-2}\right]
$$

for $0.21 \mathrm{~mm} \leq D \leq 4.51 \mathrm{~mm}, 0.28 \leq M \leq 0.64$,

- Leliavsky (1966):

$$
\tau_{c r}=166 \mathrm{D}
$$

In these formulas grain size is the basic parameter that determines the critical stress while fluid viscosity is negligible. One of the best-known and widely used tools to determine the beginning of movement of sediment grains was developed by Shields (1936). In view of the random nature of the processes that determine sediment movement, it is difficult to formulate critical shear stress analytically. Shields, as one of the first authors in fluid mechanics, applied similarity approach and dimensional analysis. He made the assumption that the difference between fluid and sediment density, diameter of particles, kinematic viscosity of fluid and acceleration due to gravity were important for initiation of particles movement. Two dimensionless parameters are expressed by these variables: Reynolds number and shear stress.

$$
\begin{gathered}
R e^{*}=U D v^{-1} \\
\tau *=\tau\left[\left(\rho_{s}-\rho\right) g D\right]^{-1}
\end{gathered}
$$

Shields assumed that when a sediment particle is about to move, the following dynamic similarity law must be true:

$$
\tau *=f\left(R e^{*}\right)
$$

The curve describing this relation was determined experimentally and is known as the Shields diagram. Due to the fact that critical stress and critical shear velocity are interchangeable, the above relationship remains implicit. There are several explicit formulations of the equation describing the Shields diagram; among them the best-known are those by Brownlie (1981), van Rijn (1993), Soulsby \& Whitehouse (1997) and Dey (2011) that describe the critical Shields parameter as a function of the parameter $D^{*}$, which is a dimensionless particle diameter:

$$
\tau_{\mathrm{cr}}^{*}=f\left(D^{*}\right)
$$

Brownlie (1981):

$$
\tau_{c r}^{*}=0.22 D_{B}^{*-0.6}+0.06 \exp \left(-17.77 D_{B}^{*-0.6}\right)
$$

Van Rijn (1993):

$$
\tau^{*}=0.14 D_{R}^{*-0.64}
$$

definition for $4<D^{*}<10$ corresponding to considered conditions

Soulsby \& Whitehouse (1997):

$$
\tau^{*}{ }_{c r}=0.24 D_{R}^{*}{ }^{-1}+0.055\left(1-\exp \left(-0.02 D_{R}^{*}\right)\right)
$$

Where $D^{*}(D, \Delta, \mathrm{v})$ is defined as:

Brownlie (1981):

$$
D_{B}^{*}=D^{3 / 2} \Delta^{1 / 2} \mathrm{~g}^{1 / 2} \mathrm{v}^{-1}
$$

Van Rijn (1993):

$$
D_{R}^{*}=D \Delta^{1 / 3} \mathrm{~g}^{1 / 3} \mathrm{v}^{-2 / 3}
$$

The values of $\tau_{c r}$ calculated based on Eq. 9a-9c are similar, which is presented in Figure 1. Based on Eq. 3 and 8 it is possible to estimate critical flow ve-

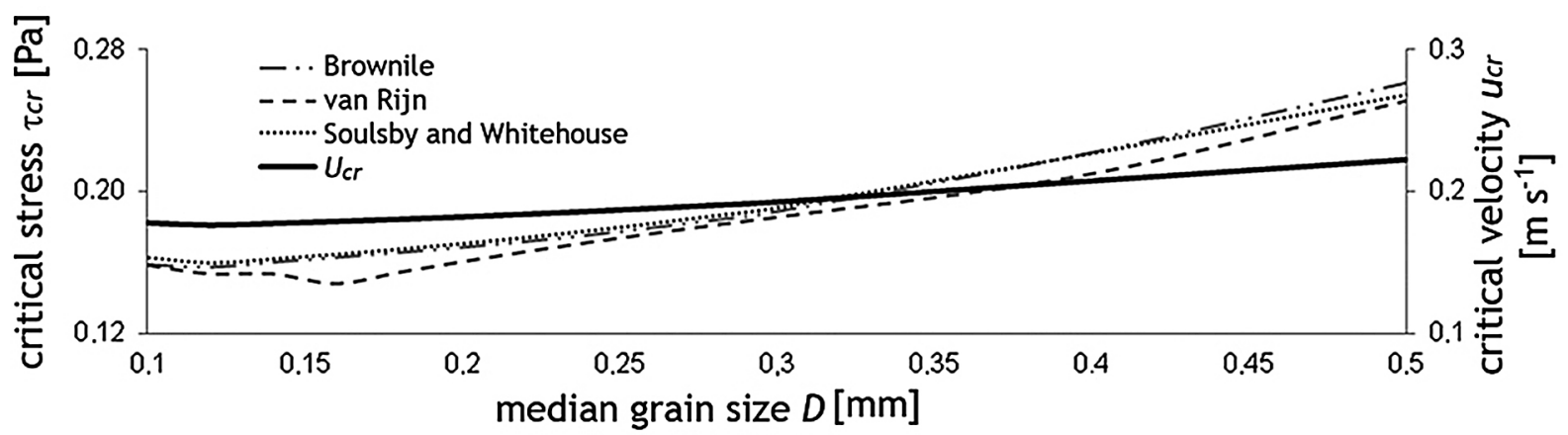

Fig. 1. Critical shear stress as a function of median grain size and velocity that leads to such stresses, estimated for $\tau_{e r}$ by Soulsby \& Whitehouse (1997). 
locity which leads to critical shear stress. In Figure $1 u_{c r}$ (estimated from $\tau_{c r}$ by Soulsby \& Whitehouse, 1997) for different grain sizes is presented.

\subsection{Friction factor}

The classic Swart (1974) formula is used in order to estimate the value of the friction coefficient $\left(f_{w}\right)$ :

$$
\ln \left(f_{w}\right)=-5.977+5.213(a / r)^{-0.194}
$$

where $a=u_{b} T \cdot(2 \Pi)^{-1}$ is the free stream amplitude, $u_{b}$ is the amplitude of wave orbital velocity at the bottom and $r$ is bed roughness; $r=k_{s}$ (Nikuradse roughness), where $k_{s}=2.5 D$ was adopted. Madsen (1994) proposed a formula for friction factor for combined wave-current bottom boundary layer flows based on theoretical solution of the boundary layer equation. In the absence of current and for wave conditions considered in the present study, the Madsen formula is analogous to the Swart formula, with slightly different coefficients (details are presented below):

$$
\ln \left(f_{w}\right)=-7.30+5.61(a / r)^{-0.109}
$$

There is one more difference in Swart's and Madsen's approaches. In the latter the root-meansquare value of the orbital velocity near the bottom $u_{r m s}$ is used and in the first $-u_{b}=\sqrt{2} u_{r m s}$.

\subsection{Bedload transport models}

The classic models used in the present paper assume that the driving force of sediment transport is shear stress at the bottom and that sediment transport is a function of effective bottom stress which is defined as the difference between current stress (time-dependent) and critical stress value. Only in the Engelund \& Hansen (1967) model was the critical stress value for initiation of sediment transport not included. The models by Du Boys (1879), Meyer-Peter and Müller (1948) and Ribberink (1998) were developed for bedload, while the one by Engelund and Hansen considered total load.

\subsubsection{Du Boys (1879)}

The first attempts to describe sediment transport associated with stream flows (flows in rivers) were made in the late nineteenth century. In 1879 Paul Du Boys proposed a bedload transport model that was the first one that was not purely empirical:

$$
Q_{m}=A \tau_{0}\left(\tau_{0}-\tau_{c r}\right)
$$

The above formula allows to determine the rate of mass transport per unit width of the channel. A is the sediment-characteristic parameter the value of which can be determined based on the Schoklitsch (1914) formula:

for stress expressed in $\left[\mathrm{kgm}^{2}\right]: A=0.54\left[\left(\rho_{s}-\vartheta\right) g\right]^{-1}$ for stress expressed in $\left[\mathrm{kgm}^{3} \mathrm{~s}^{-2}\right]: A^{\prime}=A g^{-2}$

The dimensionless transport determined with the use of Du Boys' and Schoklitsch's formulas is described by the following formula:

$$
Q^{*}=A^{*} \tau^{*}\left(\tau^{*}-\tau^{*}{ }_{c r}\right)
$$

where $A^{*}=0.54 \rho(\Delta D / g)^{1 / 2}$.

Another approach assumes a dependency between the $A$ coefficient and grain diameter (Straub, 1935): $A \sim D^{-3 / 4}$. Du Boys model was verified experimentally in 1924 by Armin Schoklitsch. A generalisation of the model was made by $\mathrm{O}^{\prime}$ Brien \& Rindlaub (1934).

\subsubsection{Meyer-Peter \& Müller (1948)}

Based on data and results of tests carried out over a period of 16 years at the Laboratory of Hydraulic Research and Soil Mechanics (Swiss Federal Institute of Technology, Zürich), as well as on their own experiments, Meyer-Peter \& Müller (1948) developed an empirical formula (MPM) that characterised bedload transport in a river as a function of shear stress:

$$
Q^{*}=A^{*}\left(\tau^{*}-\tau^{*}{ }_{c r}\right)^{3 / 2}
$$

This formula does not include the adjustment related to the lateral walls of the channel and the existence of bottom forms proposed by MPM. Based on the correlation with measurements for well-sorted, gravel-sized sediments (about $5 \mathrm{~mm}$ ), Meyer-Peter \& Müller designated constants $A^{*}=8$ and $\tau_{c r}^{*}=0.047$. Wong (2003) and Wong \& Parker (2006) proposed new constants allowing for a better fit of the formula to measured data: $A^{*}=3.97$ and $\tau_{c r}^{*}=0.0495$. To adjust the formula to different grain sizes, in the present paper $\tau_{c r}^{*}$ is determined based on the van Rijn formula. The results of tests carried out by Meyer-Peter \& Müller (1948) showed that the formula can be used to predict sediment transport under natural conditions and thus it is still widely used in basic research and engineering applications. 


\subsubsection{Ribberink (1998)}

Ribberink's model for bedload transport can be used both for stationary and oscillatory flows. Demersal stresses are expressed by the dimensionless Shields parameter:

$$
Q^{*}=m\left(\tau^{*}-\tau^{*}{ }_{c r}\right)^{n}
$$

where $m=10.4, n=1.67$.

\subsubsection{Engelund \& Hansen (1967)}

The semi-empirical formula proposed by Engelund \& Hansen (1967) is based on the assumption that sediment discharge is equal to changes in bed elevation. Such approach leads to a formula in which total transport is a function of shear stress raised to the power of 2.5 , and is inversely proportional to the friction coefficient $f_{\mathrm{w}}$.

$$
Q^{*}=0.1 f_{w}-\tau^{* 5 / 2}
$$

\subsection{Area of interest}

The study area is located in the southern Baltic, within Polish Marine Areas (see Fig. 2) and adjacent to the coastline in the vicinity of the village of Lubiatowo, where the Coastal Research Station (a field laboratory) of the Institute of Hydro-Engineering of the Polish Academy of Sciences (IBW PAN) is based. It is an example of typical southern Baltic sandy coast (i.e., 76 per cent of the Polish coast; see Uścinowicz et al., 2004), exposed to winds from northwesterly directions. Since there are no tides, it is an ideal site to investigate the impact of wave processes on bedload transport.

According to measurements supplied by IBW PAN, the shore is relatively stable, although a very gentle erosive tendency has been observed over recent years. There is a gentle slope of the sea bottom, approximately 1.5 per cent (locally, at the shoreline, with a maximum of 4 per cent). Granulometric variability of the sediment was determined during the 2001 field campaign (Ostrowski et al., 2013). The sediment is quite uniform with a diameter oscillat-

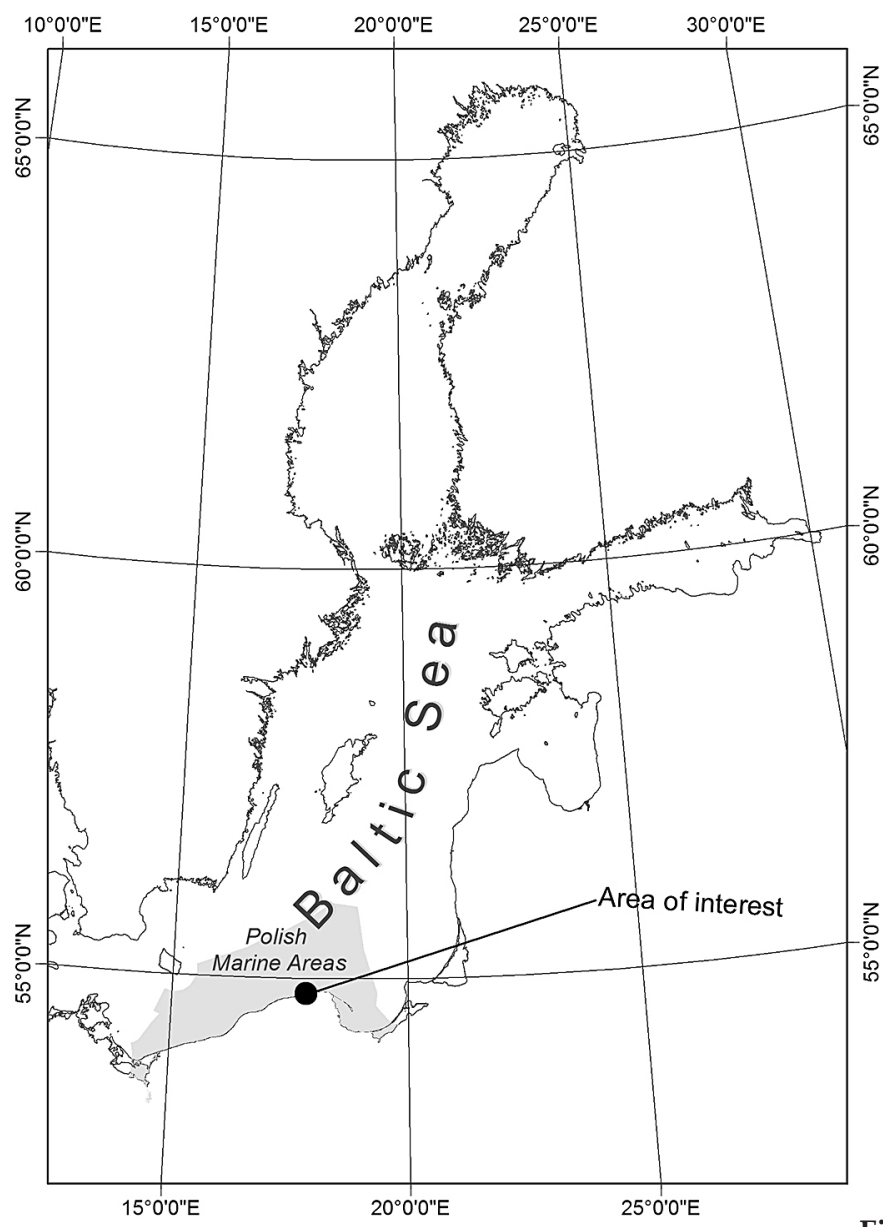

Fig. 2. Area of interest.

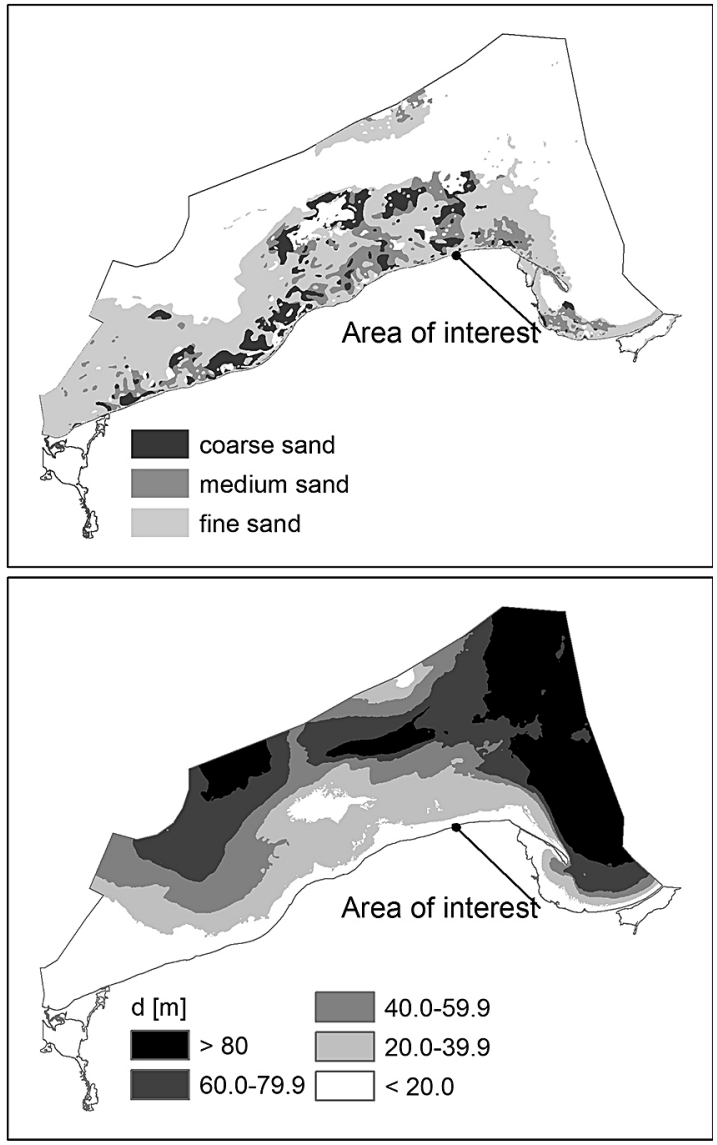

Fig. 3. Spatial distribution of sediment grain sizes in the area of interest. 
ing around an average value of $D=0.22 \mathrm{~mm}$. The further away from the shore the larger sediment grains are (to a maximum of about $0.8 \mathrm{~mm}$; see Fig. 3). Since there are no particles with a diameter smaller than $0.01 \mathrm{~mm}$ there are hardly any cohesive effects (Miedema, 2013).

For conditions in the study area considered were: grain size $D=0.22 \mathrm{~mm}$ and shear velocity $u^{*}$ up to $0.06 \mathrm{~m} \cdot \mathrm{s}^{-1}$ (Table $\left.1, u^{*}=\left(\tau \rho^{-1}\right)^{0.5}\right)$, settling ve-

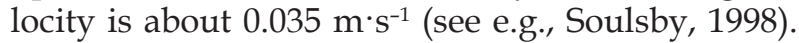
Thus, the concentration of suspended load is small (up to about 20 per cent) and suspended sediments are present mostly in the bottom layer (see Rouse profiles; Soulsby, 1998). Therefore, it can be assumed that the prevailing mode of transport is bedload transport (Rouse number $>2: 5$ ) (Anderson \& Anderson, 2010).

Along the section of the shore in the area of interest, typically four permanent and a single temporary offshore bars can be noted. The first stable offshore sandbar occurs at a distance of approximately 100-120 m from the shoreline, the second at approximately $200 \mathrm{~m}$, the third at $400-450 \mathrm{~m}$ and the fourth, and possibly fifth at 650 to $850 \mathrm{~m}$ from the shoreline, respectively. The depth of the water at $1 \mathrm{~km}$ from the shoreline is about $8 \mathrm{~m}$ and it increases to about $15-17 \mathrm{~m}$ at $2 \mathrm{~km}$ and to $25 \mathrm{~m}$ at 9 $\mathrm{km}$. The bottom profile is relatively uniform along the coastline (Ostrowski \& Pruszak, 2003).

For the coastal area of the southern Baltic (at depths in the order of $20 \mathrm{~m}$ ) under stormy conditions, significant wave height $\left(H_{\mathrm{s}}\right)$ of the major waves is generally in the range of 2 to $3.5 \mathrm{~m}$ with periods varying between 5 and $7 \mathrm{~s}$ at the seaward boundary of the depth of $7 \mathrm{~m}$. As a result of subsequent transformation, the mean wave height falls to $1-1.5 \mathrm{~m}$ at a depth of 2-3 $\mathrm{m}$ (around the second and third bars), while the mean wave period becomes 4-5 s. Waves with $H_{s}$ greater than $1 \mathrm{~m}$ come mainly from the W-WNW and N-NNE (Pruszak \& Zeidler, 1995; Paplińska-Swerpel, 2003). These results were confirmed by Pruszak et al. (2008) on the basis of a field survey conducted in 2006.

According to measurements for the study area (Pruszak \& Zeidler, 1995) the longshore sediment transport under weak waves conditions, with breaker height much lower than $1 \mathrm{~m}$ occurs only in the area up to $200 \mathrm{~m}$ offshore with a rate of $5-8 \mathrm{~kg}(\mathrm{~m} \cdot \mathrm{h})^{-1}$. For waves with a mean breaker height slightly below $1 \mathrm{~m}$, sediment transport rate varies between $5-30 \mathrm{~kg}(\mathrm{~m} \cdot \mathrm{h})^{-1}$; weaker sediment transport may also appear further offshore. During storms the rate of sediment transport reaches 100 $\mathrm{kg}(\mathrm{m} \cdot \mathrm{h})^{-1}$ between the shore line and fourth bar and decreases to $30 \mathrm{~kg}(\mathrm{~m} \cdot \mathrm{h})^{-1}$ about the fifth bar. It should be noted that westerly winds were predominant during this experiment.

\subsection{Wave field modelling}

In order to estimate water flow velocity related to wind wave conditions, wave field modelling was conducted for several wind conditions. Across the entire Baltic Sea WAM model (WAMDI Group, 1988) was used. This is a third-generation wave model, which computes spectra of random, short-crested, wind-generated waves. It is the first model that solves the complete action density equation, including non-linear wave-wave interactions. The WAM wave prediction model has become a standard tool for operational wave prediction as well as for research and engineering applications. In the present paper, the WAM Cycle 4.5 was used (Günther \& Behrens, 2012) with horizontal resolution of five nautical miles (see also Cieślikiewicz et al., 2014).

In the coastal zone the SWAN model was used (Simulating WAveNearshore; Booij et al., 1996), which is a third-generation wave model that computes random, short-crested, wind-generated waves in coastal regions and inland waters. The model takes into account wave propagation in time and space, shoaling, refraction due to current and depth, frequency shifting due to currents and non-stationary depth, wave generation by wind, three- and four-wave interactions, white capping, bottom friction and depth-induced breaking, dissipation due to vegetation, wave-induced set-up, transmission through and reflection against obstacles, as well as diffraction (Urbański et al., 2008). Nearshore wave conditions were modelled with SWAN model by three nestings: WAM with SWAN ( $\sim 20 \mathrm{~km}$ along shore $\sim 12 \mathrm{~km}$ cross-shore, resolution $500 \mathrm{~m})$, SWAN with SWAN $(\sim 10[\mathrm{~km}] \times 6 \mathrm{~km}$, resolution $1,000 \mathrm{~m})$ and again with SWAN $(\sim 0.7 \mathrm{~km}$ $\times 2.6 \mathrm{~km}$, resolution $10 \mathrm{~m}$ ) (see Gic-Grusza \& Dudkowska, 2014). During all simulations an artificial uniform wind field over the whole area of interest, for selected wind direction, was applied. All the SWAN simulations were performed in a stationary mode, and the results are given for the peak of an assumed, artificial storm.

\subsection{Test conditions}

The main results are presented for westerly and northerly winds of $14.5 \mathrm{~m} \cdot \mathrm{s}^{-1}$, which are very strong winds measured in the coastal zone of Polish 


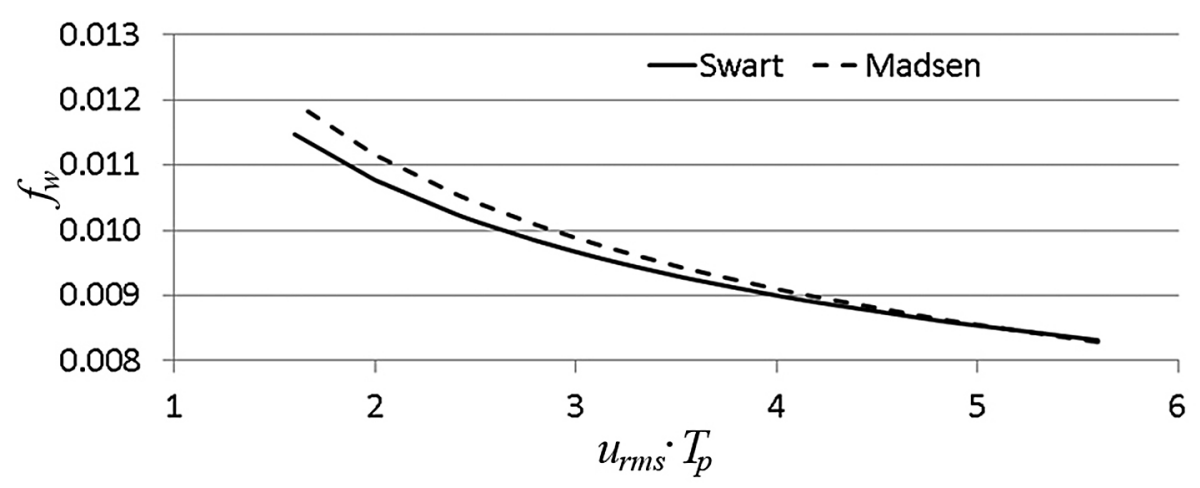

Fig. 4. Friction coefficient $f_{w}$ as a function of product of the root-mean-square near-bottom wave orbital velocity $u_{r m s}$ and wave period $T$, for grain size $D=0.22 \mathrm{~mm}$, based on two approaches (details in text).

Marine Areas (Tarnowska, 2011) that result in the highest value of orbital velocity near the bottom. These test cases were chosen to show the maximum difference between the results discussed. Moreover, winds from the northwesterly sectors (W, WNW, $\mathrm{NW}, \mathrm{NNW}, \mathrm{N}$ ) are dominant in the area of interest, which makes it possible to compare estimated values and measurements.

The bottom root mean square orbital velocities $\left(u_{r m s}\right)$, derived from the output of SWAN model, for this condition varies from 0.3 to $0.8 \mathrm{~m} \cdot \mathrm{s}^{-1}$ with local maxima on the bars; $u_{r m s}$ values for northerly wind are higher than for westerly wind. Waves approaching the shore from the north are higher onshore (significant wave height $H_{\mathrm{s}}$ about $3.5 \mathrm{~m}$ ) in comparison to these approaching from the west $\left(H_{s}\right.$ about $2.2 \mathrm{~m}$ ). These differences are smaller after two wave breaks on the fourth and third bar (about 760 $\mathrm{m}$ and $610 \mathrm{~m}$ from shoreline). In the area up to the second bar, about $220 \mathrm{~m}$ from the shoreline, wave heights are comparable for both considered directions (about $1.5 \mathrm{~m}$ ). The other modelled parameterpeak period $T_{p}$ is about $4-7 \mathrm{~s}$.

The friction coefficient (Eq. 11 and 12) is in the order of 0.01 (with accuracy of $10^{-2}$ ), according to both the Swart and Madsen approaches (see Fig. 4).

\section{Results}

\subsection{Bed shear stress}

Critical bed shear stress is estimated on the basis of empirical (Eq. 4a-4c) and theoretical (Shields diagram based) formulas (Eq. 9b-9c). In both cases critical bed shear stress depends on sediment grain size; in the present study $D=0.22$ $\mathrm{mm}$. According to the latter group of formulas the onset of sediment motion is associated with bottom stresses of about $0.17 \mathrm{~Pa}$ (see Fig. 5). Corresponding critical bottom flow velocity estimated based on Eq. 3 is about $18 \mathrm{~cm}^{\cdot} \mathrm{s}^{-1}$. These values are lower compared to those computed in other empirical methods discussed; critical stress: 0.24 $\mathrm{Pa}$ (USWES) and 0.36 Pa (Leliavsky), critical velocity above $20 \mathrm{~cm} \cdot \mathrm{s}^{-1}$. The Kramer formula (Eq. 4a) cannot be used because of its range of applicability. For bottom flow velocities ranging from 30 to $80 \mathrm{~cm} \cdot \mathrm{s}^{-1}$, the bottom stresses are about $0.5-3.3$ Pa (see Table 1). Bottom shear stress exceeds critical value (about $0.17 \mathrm{~Pa}$ ), thus for the specified stormy conditions sediment particles move over the entire range of velocities.

In order to determine sediment transport rate we used the value $\tau_{c r}^{*}=0.05\left(\tau_{c r}=0.17 \mathrm{~Pa}\right)$, result-

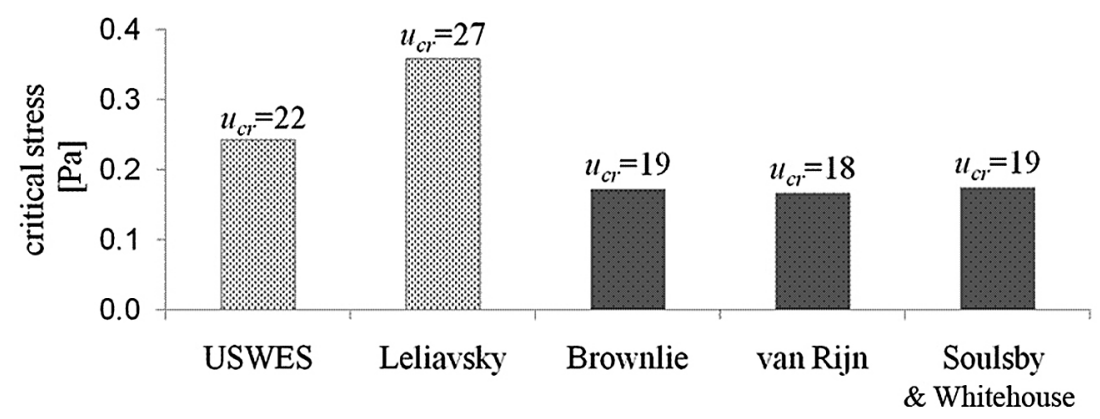

Fig. 5. Critical shear stress based on empirical formulas (dots fill) and based on Shields diagram (solid fill). Corresponding critical bottom flow velocities are presented (in $\mathrm{cm}^{-1}$ ); $D=0.22 \mathrm{~mm}, \rho=1004 \mathrm{~kg} \cdot \mathrm{m}^{-3}$. 
Table 1. Values of bottom shear stress and transport for bottom velocities considered.

\begin{tabular}{|c|c|c|c|c|c|c|c|c|c|c|}
\hline \multirow{2}{*}{$\frac{U}{\left[\mathrm{~m} \mathrm{~s}^{-1}\right]}$} & \multirow{2}{*}{$\frac{\tau}{[\mathrm{Pa}]}$} & \multirow[t]{2}{*}{$\tau^{*}$} & \multicolumn{4}{|c|}{$Q^{*}$} & \multicolumn{4}{|c|}{$Q_{m}\left[\mathrm{~kg} \cdot(\mathrm{m} \cdot \mathrm{h})^{-1}\right]$} \\
\hline & & & du Boys & MPM & $\mathrm{EH}$ & $\begin{array}{c}\text { Ribber- } \\
\text { ink }\end{array}$ & du Boys & MPM & $\mathrm{EH}$ & $\begin{array}{c}\text { Ribber- } \\
\text { ink }\end{array}$ \\
\hline 0.3 & 0.5 & 0.1 & 0.04 & 0.1 & 0.1 & 0.2 & 5 & 12 & 8 & 21 \\
\hline 0.4 & 0.8 & 0.2 & 0.1 & 0.3 & 0.3 & 0.6 & 18 & 40 & 33 & 78 \\
\hline 0.5 & 1.3 & 0.4 & 0.4 & 0.7 & 0.8 & 1.5 & 47 & 88 & 100 & 190 \\
\hline 0.6 & 1.9 & 0.5 & 0.8 & 1.3 & 2.0 & 3.1 & 103 & 162 & 249 & 376 \\
\hline 0.7 & 2.5 & 0.7 & 1.6 & 2.2 & 4.4 & 5.4 & 196 & 268 & 538 & 656 \\
\hline 0.8 & 3.3 & 0.9 & 2.8 & 3.3 & 8.6 & 8.6 & 339 & 410 & 1048 & 1053 \\
\hline
\end{tabular}

ing from formulas based on the Shields diagram. The corresponding critical flow velocity is about $18 \mathrm{~cm} \cdot \mathrm{s}^{-1}$ (see Fig. 5), which is overstated with respect to that recorded in the literature, for example 8-12 $\mathrm{cm} \cdot \mathrm{s}^{-1}$ in Pruszak \& Zeidler (1995) and about $2 \mathrm{~cm} \cdot \mathrm{s}^{-1}$. This parameter has the greatest impact on transport in the case of small flow velocities. In particular for a flow velocity of about $30-40 \mathrm{~cm} \cdot \mathrm{s}^{-1}$, the change of critical flow velocity from 8 to $18 \mathrm{~cm} \cdot \mathrm{s}^{-1}$ is related to a decrease of transport of about 25-40 per cent. In contrast, such a change in high velocities range $\left(80-120 \mathrm{~cm}^{\cdot} \mathrm{s}^{-1}\right)$ causes a transport decrease of less than 8 per cent.

\subsection{Wave-induced bedload transport in the study area}

Instantaneous mass bedload transport in the cross section of the coastal area of interest is calculated based on the formulas discussed (see Eq. 14-17). As the main factor determining $Q^{*}$ is flow velocity, values of transport together with $u_{r m s}$ and significant wave height $H_{s}$ are presented (see Figs. $6,7)$. For westerly and northerly winds, values of transport calculated based on the Ribberink formula are the highest. For westerly winds sediment transport values calculated based on the Du Boys and MPM are about $100 \mathrm{~kg}(\mathrm{~m} \cdot \mathrm{h})^{-1}$ between shore line and fourth bar and decreases about the fifth bar, which is similar to the values defined for storm conditions (see section 2.5). For northerly winds of $14 \mathrm{~m} \cdot \mathrm{s}^{-1}$, the resulting values are higher than calculated and measured for westerly wind, especially in the case of $\mathrm{EH}$ and Ribberink formulas (i.e., up to $\left.900 \mathrm{~kg}(\mathrm{~m} \cdot \mathrm{h})^{-1}\right)$.

Cross-shore distribution of bedload transport rate for westerly winds is consistent with earlier studies and measurements (see e.g., Pruszak \& Zeidler, 1995). Spatial distribution of estimated values and directions of volumetric wave-induced bedload transport is presented in Figure 8.

Since the cross-shore bottom profile is almost uniform in longshore direction, values discussed above are representative of the entire area of interest. The highest values of transport occur in the vicinity of the second bar during northerly winds $(\mathrm{N}$, NNW).

\subsection{A unified formula for bedload sediment transport}

The sediment transport rate estimated on the basis of a bottom stress approach is determined mainly by near-bottom velocities. Dimensionless bed load transport $Q^{*}$ (Einstein parameter), calculated by four formulas discussed in the present paper for a considered range of velocities $0.3-0.8 \mathrm{~m} \cdot \mathrm{s}^{-1}$ and additionally for $1.2 \mathrm{~m} \cdot \mathrm{s}^{-1}$, is presented in Figure 9 and Table 1.

The Du Boys formula gives the lowest, whereas Ribberink's formula yields the highest values of

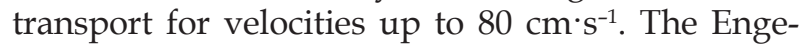
lund and Hansen and MPM formulas present intermediate values, but for high velocities (about 120 $\mathrm{cm} \cdot \mathrm{s}^{-1}$ ) the result of EH is the greatest. There is no simple rule which allows to choose one formula well fit to the whole range of velocities. Thus, we propose a unified form of bed load transport formulas:

$$
Q^{*}=C^{*} \tau^{* p}-C^{*} f\left(\tau, \tau, r^{\prime} p\right)
$$

Such a compact form simplifies the process of fitting coefficients to measured values. $C^{*}$ is a dimensionless constant (MPM, Ribberink) or is dependent on local conditions such as density of water and sediments, grain size, friction factor $(\mathrm{Du}$ Boys, $\mathrm{EH}), p$ is a real number and $\mathrm{f}$ is a function of the form resulting from Newton's generalised binomial theorem. The set of $C^{*}$ and $p$ coefficients in 

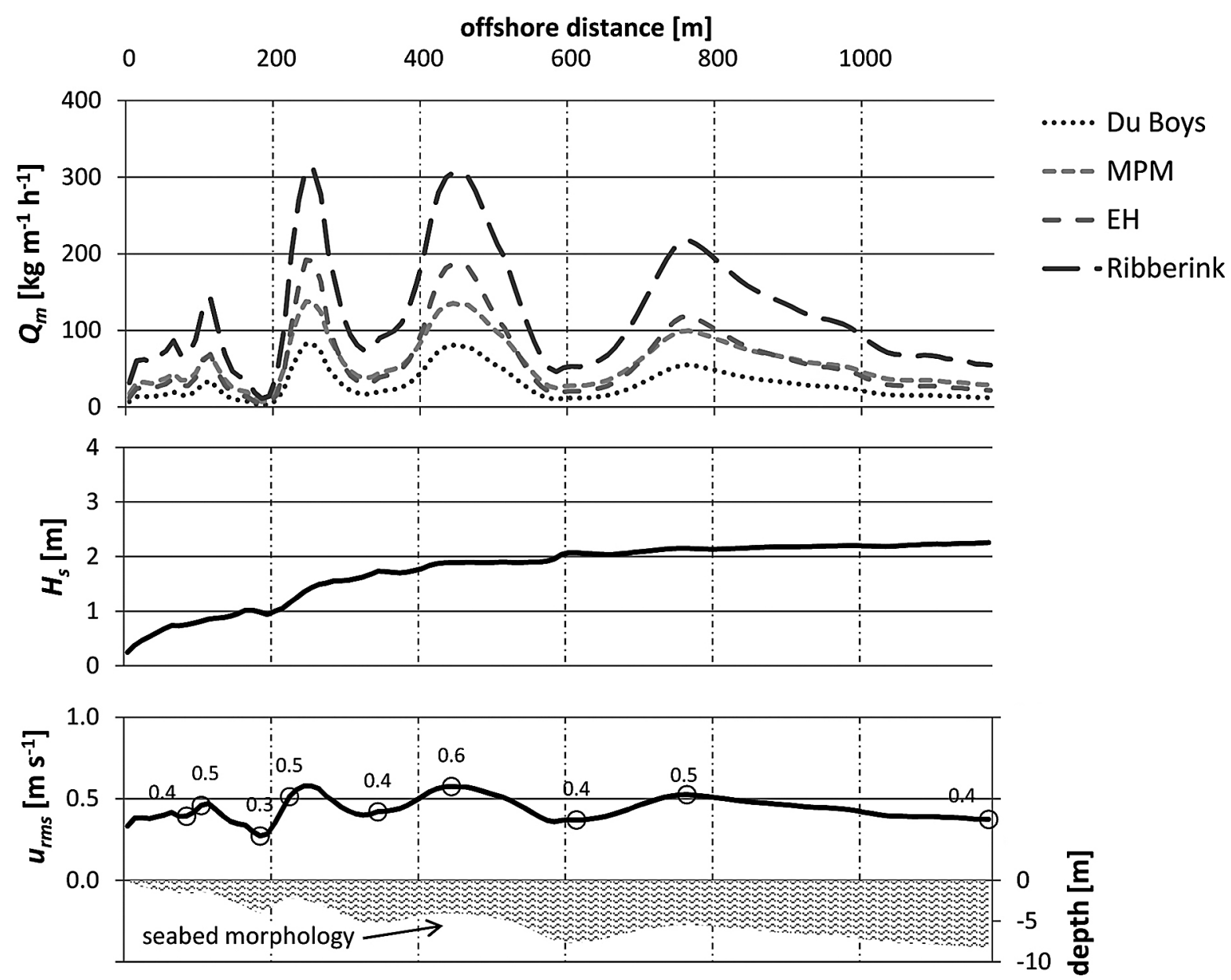

Fig. 6. Cross-shore distribution of mass wave-induced bedload transport by a number of methods, together with depth profile, $u_{r m s}$ and significant wave height for westerly wind (speed $14.5 \mathrm{~m} \mathrm{~s}^{-1}$ ). Labels indicate velocity values for bars and troughs in the cross-shore profile.

considered models for area of interest environmental conditions is presented in Table 2. Due to Eq. 18 transport $Q^{*}$ depends on the $p$ power of the shear stress $\tau^{*}$ (this part will be called $Q_{1}^{*}$ ) and is reduced by the $f$ function (this part will be called $Q_{2}^{*}$ ). Figure 10 shows the impact of the choice of $p$ power on the results (the $Q^{*}$ transport). As flow velocity is the main factor determining shear stress, $Q^{*}$ as the function of $U$ is shown for several $p$ parameters (chosen from the range proposed in classic models; see Table 2). The parameter $p$ has the most marked impact on the value of transport for flow velocities up to about $0.6 \mathrm{~m} \mathrm{~s}^{-1}$, for which Shields parameter $\tau^{*}<0.5$ (see Table 1). Higher values of $p$ provide smaller $Q_{1}^{*}$. In contrast, for flow velocities in excess of about $1 \mathrm{~m} \cdot \mathrm{s}^{-1}$, for which Shields parameter $\tau^{*}>$ 1.4 , higher values of $\mathrm{p}$ provide greater $Q^{*}$ addend.

In the intermediate range of velocities the value of $\mathrm{p}$ power does not influence transport considerably. In accordance with the above dependencies, in small velocity range the Engelund \& Hansen formula yields low values of transport. This is caused by the highest $p=2.5$ even despite the high $C^{*}=10$ and $f=0$. Given that this formula accounts for total transport, the bedload transport is considerably lower than estimated by other formulas for small flow velocities.

In order to estimate the contribution of $Q_{2^{\prime}}^{*}$ the ratio $Q_{2}^{*} / Q_{1}^{*}$ for considered velocity range was calculated (see Fig. 11). The Engelund \& Hansen model does not contain $f$ function ( $Q$ independent on critical shear stress. For any other model $\mathrm{f}$ function takes a relatively large values $\left(Q_{2}^{*}>10 \% Q_{1}^{*}\right)$ for low flow velocities (lower than $0.5-0.6 \mathrm{~m}^{-1} \mathrm{~s}^{-1}$ ). This is due to the fact that bottom stresses are close to critical values. Otherwise, for high velocities (greater than $\left.0.5-0.6 \mathrm{~m}^{\cdot} \mathrm{s}^{-1}\right) f$ element is small $\left(Q_{2}^{*}<\right.$ $\left.10 \% Q_{1}^{*}\right)$ and can be ignored for many purposes.

From this it follows that for high flow velocities $C^{*}$ constant has the greatest influence on the results. 

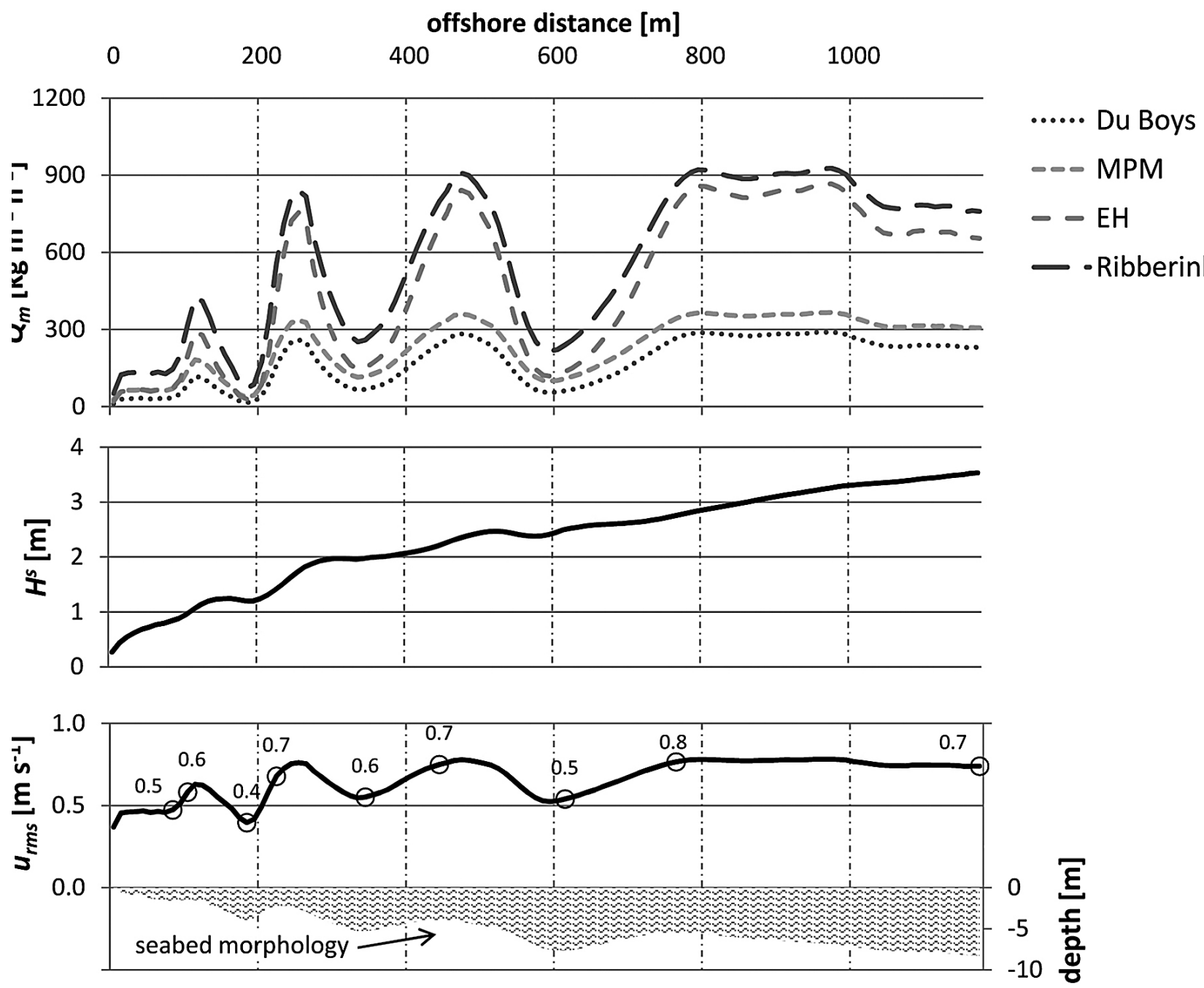

Fig. 7. Cross-shore distribution of mass wave-induced bedload transport by a number of methods, together with depth profile, $u_{r m s}$ and significant wave height for northerly wind (speed $14.5 \mathrm{~m} \cdot \mathrm{s}^{-1}$ ). Labels indicate velocity values for bars and troughs in the cross-shore profile.

$\mathbf{N}$

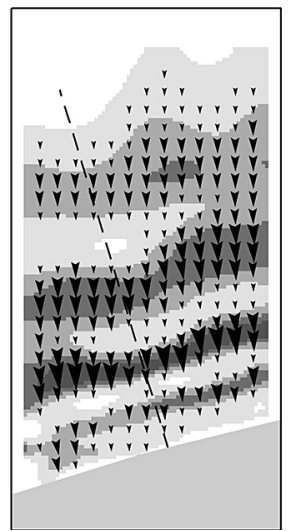

NNW

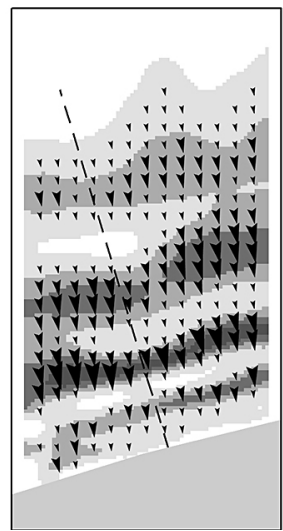

NW

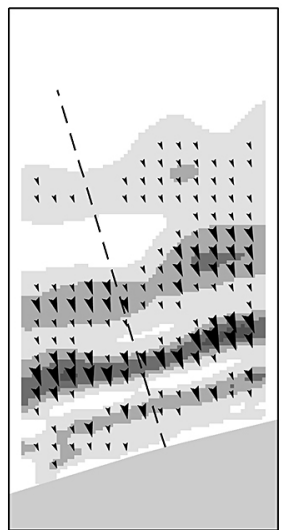

WNW

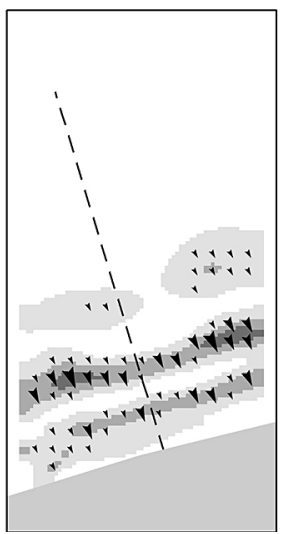

W

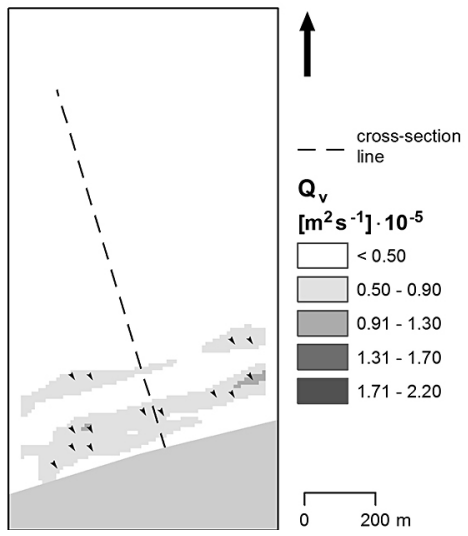

Fig. 8. Spatial distribution of estimated values of volumetric bedload transport for wind conditions considered (directions: N, NNW, NW, WNW, W; speed $14.5 \mathrm{~ms}^{-1}$ ) based on MPM formula; dashed line indicating location of section presented in Figures 6 and 7. 


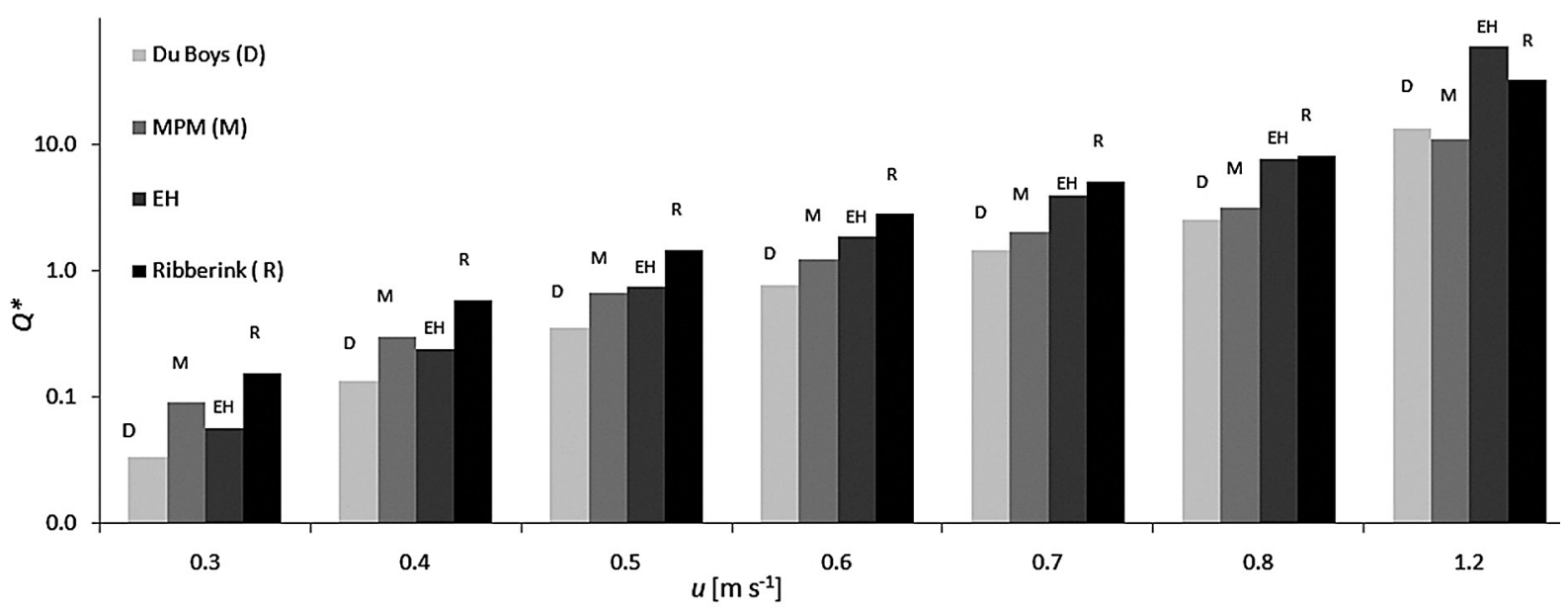

Fig. 9. Dimensionless transport by formulas examined for bottom flow velocities in the range $0.3-0.8 \mathrm{~ms}^{-1}$, and addi-

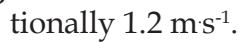

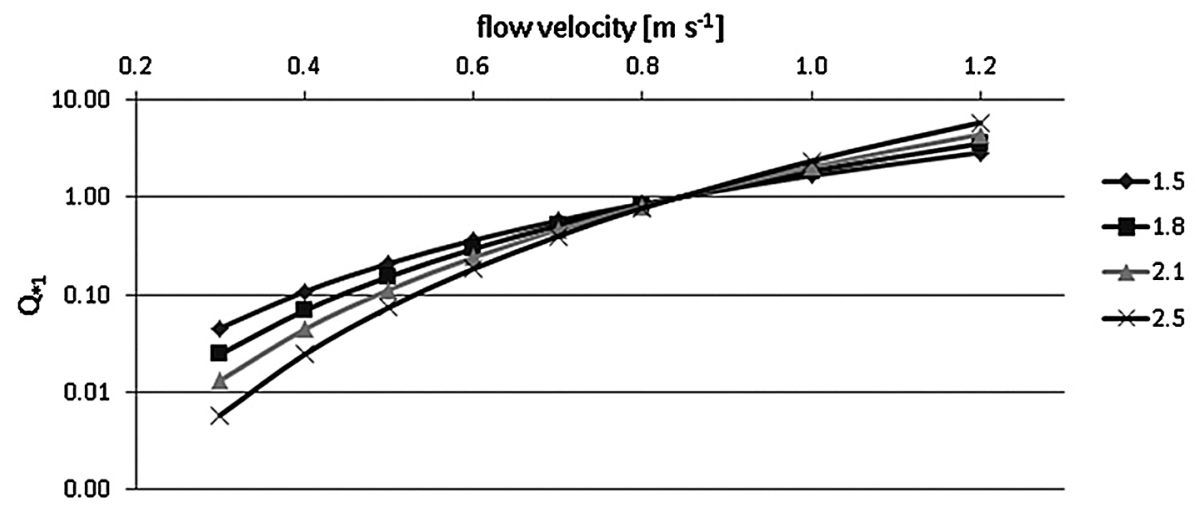

Fig. 10. The dimensionless bed load transport $Q_{* 1}=C^{*} \tau_{*}^{p}$ as a function of flow velocity for several values of $p$ power (1.5, $1.8,2.1,2.5), C^{*}=1$.

Particularly noteworthy is the fact that small variations in velocities lead to large differences in the calculated transport. This is due to the fact that the velocity is included in formulas in the power of $2 p$, namely 4.0, 3.0, 5.0 and 3.34 for Du Boys, MPM, EH and Ribberink models, respectively.
Table 2. Coefficients in the unified formula for transport (Eq. 16) which lead to classic models considered.

\begin{tabular}{lcccc}
\hline & DuBoys & MPM & EH & Ribberink \\
\hline$C^{*}$ & 3.3 & 3.97 & 10 & 10.4 \\
$p$ & 2 & 1.5 & 2.5 & 1.67 \\
\hline
\end{tabular}

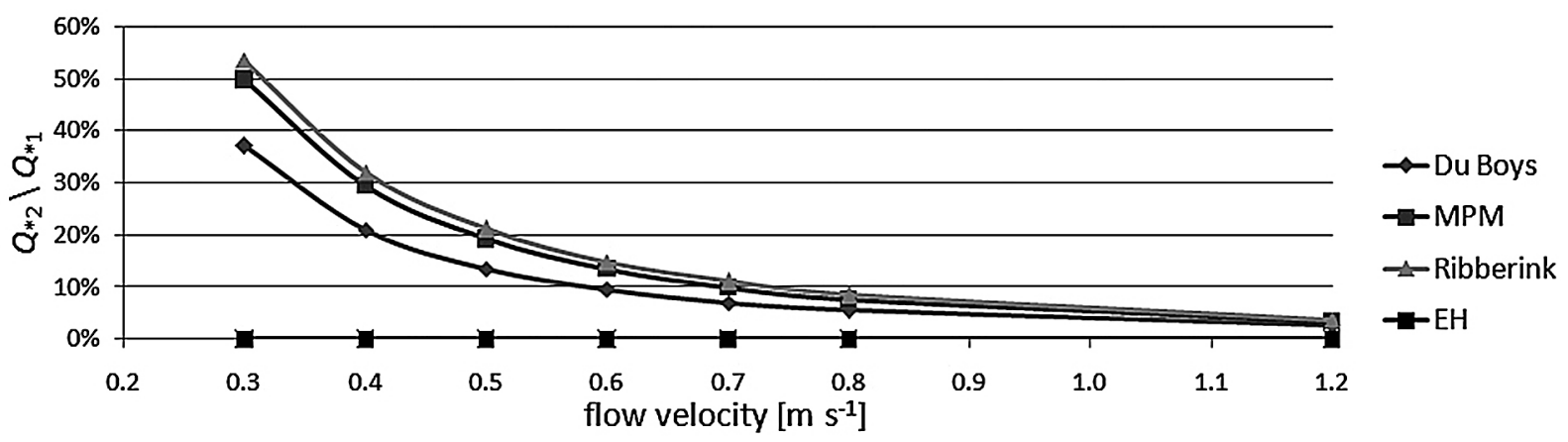

Fig. 11. The $Q_{* 2}=C_{*} f\left(\tau, \tau_{c r} p\right)$ to $Q_{* 1}=C_{*} \tau_{*}^{p}$ ratio for models considered as a function of flow velocity. 


\section{Discussion and conclusions}

The results from the theoretical investigation of wave-induced bedload transport in the Polish coastal zone are presented. The main achievement is an estimate of the sediment transport volume and direction, which is important input for engineering calculations. Our unified formula (original) for instantaneous bedload transport is based on the intercompared theoretical models.

Research was based on four classic one-gridpoint models. The formulas under consideration were validated for various environmental conditions by other researchers, but since the model parameters are strongly dependent on local conditions, a series of simulations were performed to determine their applicability within the area of interest. It has been shown that these models allow to estimate transport comparable to measured values under similar environmental conditions. Due to the lack of predominance of any considered model a unified formula for transport has been proposed (Eq. 18), which will enable to formulate the local model of transport. The results of our analysis show that for small flow velocities $p$ coefficient as well as $f\left(\tau_{c r}\right)$ function need to be carefully adjusted, while for high flow velocities (storm conditions) these factors are not very influential. $C^{*}$ constant should "scale" the transportation range to the measurement data. For storm conditions the precise choice of $p$ parameter, $f$ function as well as critical flow velocity does not influence the estimated transport significantly. The proper values of $C^{*}$ and $p$ parameters and $f$ function form should be calibrated based on the results of field measurements.

Given that the rate of bedload transport is determined mainly by the value of near-bottom flow velocity, it appears that appropriate modelling of it is the main factor affecting the accuracy of the results. Moreover, it should be emphasised that wave-induced transport is only one component of the total instantaneous bedload transport. The second is current-induced transport which - in the study area - is similar in order of magnitude and different direction. Therefore, any natural continuation of the present study should determine the value and direction of bedload transport taking into account wave-induced currents velocities. For more precise sediment transport estimates suspended load should be also considered.

\section{Acknowledgements}

We wish to thank the Institute of Hydro-engineering of the Polish Academy of Sciences for providing data on hydro- and morphodynamics in the Polish coastal zone which is the basis for the calculations presented and for result verification. This research has been supported by the Polish National Centre for Research and Development as part of the project "Development of a predictive model of morphodynamic changes in the coastal zone", based on decision no. DEC-2011/01/D/ST10/07668.

\section{References}

Anderson, R.S. \& Anderson S.P., 2010. Geomorphology: The Mechanics and Chemistry of Landscapes. Cambridge University Press, 651 pp.

Bakhtyar, R., Barrya, D.A., Lib, L., Jengc, D.S. \& Yeganeh-Bakhtiaryd, A., 2009. Modeling sediment transport in the swash zone: A review. Ocean Engineering 36, 767-783.

Booij, N., Holthuijsen, L.H. \& Ris, R.C., 1996. The SWAN wave model for shallow water. Proceedings of the $25^{\text {th }}$ International Conference on Coastal Engineering, Orlando, USA, 668-676.

Brownlie, W.R., 1981. Prediction of flow depth and sediment discharge in open channels. W.M. Keck Laboratory of Hydraulics and Water Resources, California Institute of Technology, Pasadena, Report No. KH-R-43A.

Cieślak, A., 1985. Ruch rumowiska wzdłuż wybrzeża Polski [Sediment motion along the coast of Poland], Prace Instytutu Morskiego 690. Gdańsk.

Cieślikiewicz, W., Dudkowska, A., Janowczyk, R., Roščinski, V., Roziewski, S. \& Badur, J., 2014. Wind wave modelling over the Baltic Sea using WAM model and the coupled ocean circulation-wave POM model. Proceedings of the International Conference on Coastal Engineering , ASCE, Soeul, Korea, 422-428.

Davies, A.G., van Rijn, L.C., Damgaard, J.S., van de Graaff, J. \& Ribberink, J.S., 2002. Intercomparison of research and practical sand transport models. Coastal Engineering 46, 1-23.

Dey, S., 2011. Entrainment threshold of loose boundary streams. [In:] P. Rowinski (Ed.), Experimental methods in hydraulic research. series: Geoplanet: Earth and Planetary Sciences, 29-48. Springer.

Du Boys, P., 1879. Le Rhone et les rivieres a lit affouillable. Annales des Ponts et Chausse'es 18, 141-195.

Einstein, H.A., 1950. The bed-load function for sediment transportation in open channel flows. Technical Bulletin 1026, 1-71.

Engelund, F. \& Hansen, E., 1967. A monograph on sediment transport in alluvial streams. Teknisk Forlag, Copenhagen, $65 \mathrm{pp}$.

Gic-Grusza, G. \& Dudkowska, A., 2014. Modeling of wind wave induced sediment transport in the coastal zone of Polish marine areas (Southern Baltic). Baltic International Symposium (BALTIC), 2014 IEEE/OES, Tallin, 1-5. 
Gic-Grusza, G., Kryla-Straszewska, L., Urbański, J. \& Węsławski, J.M. (Eds), 2009. Atlas of Polish marine area bottom habitats. Environmental valorization of marine habitats. Broker-Innowacji, Gdynia, 180 pp.

Günther, H. \& Behrens, A., 2012: The WAM Model - Validation Document, Version 4.5.4. Institute of Coastal Research Helmholtz-Zentrum Geesthacht.

Kramer, H., 1935. Sand mixtures and sand movement in fluvial models. Transactions of the American Society of Civil Engineers 100, 798-878.

Leliavsky, S., 1966. An introduction to fluvial hydraulics. Dover Publications, New York, 257 pp.

Madsen, O.S., 1994. Spectral wave-current bottom boundary layer flows. Proceedings of $24^{\text {th }}$ International Conference on Coastal Engineering, ASCE, Kobe, 384-398.

Meyer-Peter, E. \& Müller, R., 1948. Formulas for bed-load transport. Proceedings of $2^{\text {nd }}$ Meeting, IAHR, Stockholm, 39-64.

Miedema, S.A., 2013. Constructing the Shields Curve, Part C: Cohesion by Silt, Hjulstrom, Sundborg. WODCON XX, Brussels, 1-15.

O'Brien, M.P. \& Rindlaub, B.D., 1934. The transportation of bedload by streams. Transaction of the American Geophysical Union 100, 393-419.

Ostrowski, R., Piotrowska, D., Schönhofer, J., Skaja, M., Stella, M. \& Szmytkiewicz, P., 2013. Parametry procesów hydrodynamicznych i morfodynamicznych w rejonie Morskiego Laboratorium Brzegowego w Lubiatowie [Hydrodynamic and morphodynamic processes parameters in the vicinity of the Coastal Research Station at Lubiatowo]. Instytut Budownictwa Wodnego PAN, Gdańsk, $24 \mathrm{pp}$.

Ostrowski, R. \& Pruszak, Z., 2003. Coastal Research Station at Lubiatowo. Summerschool-Workshop Coastal Zone. CEM, IBW PAN. Gdańsk, 65-80.

Paplińska-Swerpel, B., 2003. Coastal Research Station at Lubiatowo. Summerschool-Workshop Coastal Zone. CEM, IBW PAN. Gdansk, Poland, 9-30.

PN-EN ISO 14688-1:2006/ A1:2014-02E Geotechnical investigation and testing - Identification and classification of soil - Part 1: Identification and description - Amendment 1 (ISO 14688-1:2002/Amd 1:2013), Warsaw, Poland, $12 \mathrm{pp}$.

Pruszak, Z., Szmytkiewicz, P., Ostrowski, R., Skaja, M. \& Szmytkiewicz, M., 2008. Shallow-water wave energy dissipation in a multi-bar coastal zone. Oceanologia 50, 43-58.

Pruszak, Z. \& Zeidler, R.B., 1995. Sediment transport in various time scale. Proceedings of the $24^{\text {th }}$ International Conference on Coastal Engineering, New York 1, 25132526.

Ribberink, J.S., 1998. Bed-load transport for steady flows and unsteady oscillatory flows. Coastal Engineering 34, 59-82.
Schoklitsch, A., 1914. Uber Schleppkraft und Geschiebebewegung. Engelmann, Leipzig, 74 pp.

Shields, A., 1936. Application of similarity principles and turbulence research to bed-load movement. Mitteilungen der Preußischen Versuchsans-talt für Wasserbau, Berlin, 26 pp.

Soulsby, R., 1998. Dynamics of marine sands. Thomas Telford Publ., London, $272 \mathrm{pp}$.

Soulsby, R. \& Whitehouse, R., 1997. Threshold of sediment motion in coastal environment. Proceedings of the Pacific Coasts and Ports Conference. University of Canterbury, Christchurch, 149-154.

Straub, L.B., 1935. Discussion on sand mixtures and sand movement in fluvial models. Proceedings of the American Society of Civil Engineers 61, 101-107.

Swart, D.H., 1974. Offshore sediment transport and equilibrium beach profiles. Delft Hydraulics Laboratory Publication, $131 \mathrm{pp}$.

Tarnowska, K., 2011. Strong winds on Poland's Baltic Sea Coast. Prace i Studia Geograficzne 47, 197-204.

Urbański, J., Grusza, G., Chlebus, N. \& Kryla, L., 2008. A GIS-based WFD oriented typology of shallow micro-tidal soft bottom using wave exposure and turbidity mapping. Estuarine, Coastal and Shelf Science 78, 1, 27-37.

USWES, 1936. Flume tests made to develop a synthetic sand which will not form ripples when used in movable bed models. Technical Memorandum 99-1, US Waterways Experiment Station, Viecksburg.

Uścinowicz, S., Zachowicz, J., Graniczny, M. \& Dobracki, R., 2004. Geological structure of the southern Baltic coast and related hazards. Polish Geological Institute Special Papers 15, 61-68.

van Rijn, L.C., 1993. Principles of Sediment Transport in Rivers, Estuaries and Coastal Seas. Aqua Publications, Amsterdam, 673 pp.

Viška, M. \& Soomere, T., 2013. Simulated and observed reversals of wave driven alongshore sediment transport at the eastern Baltic Sea coast. Baltica 26, 145-56.

WAMDI Group, 1988. The WAM model - A third generation ocean wave prediction model. Journal of Physical Oceanography 18, 1775-1810.

Wong, M., 2003. Does the bedload transport relation of Meyer-Peter and Müller fits its own data? Proceedings of the $30^{\text {th }}$ IAHR Congress. Thessaloniki, 8 pp.

Wong, M. \& Parker, G., 2006. Reanalysis and correction of bed-load relation of Meyer-Peter and Müller using their own database. Journal of Hydraulic Engineering 132, 1159-1168.

Manuscript received: 5 October 2016 Revision accepted: 10 January 2017 